\title{
The structure of O-polysaccharide isolated from Cronobacter universalis
}

\section{NCTC $9529^{\mathrm{T}}$}

Kinga Marszewska ${ }^{a}$, Matgorzata Czerwicka ${ }^{a}$, Stephen J. Forsythe ${ }^{b}$,Ewelina Sałdak ${ }^{a}$, Sylwia Szulta $^{a}$, Halina Dziadziuszkoc, Karolina Ossowska ${ }^{a}$,Zbigniew Kaczyński ${ }^{a^{*}}$

aFaculty of Chemistry, University of Gdansk, Wita Stwosza 63, 80-308 Gdansk, Poland ${ }^{b}$ School of Science and Technology, Nottingham Trent University, Clifton Lane, Nottingham, NG11 8NS, United Kingdom

'Department of Molecular Microbiology and Serology, National Salmonella Centre, Medical University of Gdansk, Do Studzienki 38, 80-227 Gdansk, Poland

*Corresponding author:

E-mail address: zbigniew.kaczynski@ug.edu.pl 


\section{Abstract}

The O-polysaccharide (OPS) was isolated from Cronobacter universalis NCTC $9529^{\mathrm{T}}$, a new species in the genus Cronobacter, which was created by the reclassification of the species Enterobacter_sakazakii. Purified polysaccharide was analyzed by NMR spectroscopy $\left({ }^{1} \mathrm{H}\right.$, COSY, TOCSY, ROESY, HSQC, and HSQC-TOCSY) and chemical methods. The monosaccharide derivatives were analyzed by gas chromatography, and gas chromatographymass spectrometry. These experiments enabled the type and number of monosaccharides in the repeating unit of OPS, their positions of linkages, and absolute configuration to be determined. Together the chemical analysis established a structure of the OPS of $C$. universalis $\mathrm{NCTC} 9529^{\mathrm{T}}$

$\rightarrow 3)-\alpha-L-F u c p N A c-(1 \rightarrow 4)-\alpha-D-M a n p-(1 \rightarrow 3)-\alpha-L-F u c p N A c-(1 \rightarrow 3)-\beta-D-G l c p N A c-(1 \rightarrow$

A

B

C

D

OPS isolated from $C$. universalis was structurally characterized for the first time

Keywords: Cronobacter universalis, Cronobacter sakazakii, O-polysaccharide, structure,

NMR 
The bacterial genus Cronobacter can cause severe illness in highly vulnerable neonates, infants and the elderly. ${ }^{1}$ The organism has come to prominence due to its association with severe, although rare, neonatal infections leading to necrotizing enterocolitis (NEC), septicaemia and meningitis, which can be fatal.

The genomes of over 50 Cronobacter strains have been published and are available online by open access (www.pubmlst.org/cronobacter) ${ }^{2}$ One highly variable genomic region (ESA_01179-89) corresponds to the O-antigen gene locus. The locus contains two genes galF (UDP glucose pyrophosporylase; ESA_01177) and $r f b B$ (6-phosphogluconate; ESA_01178) which are conserved in all the Cronobacter strains, whereas the rest of the genes within the $\mathrm{O}$ antigen locus are highly divergent (Kucerova et al. 2009). ${ }^{3}$ These variations have been used in serotype specific PCR-based assays. ${ }^{4-6}$ Despite the advances in genome sequencing, the Oantigen variable region of many strains is only annotated with predicted genes, and needs experimental verification. In $C$. sakazakii, $C$. malonaticus and $C$. turicensis the lipopolysaccharide (LPS) are composed of various branched polymers, whereas they are unbranched in $C$. muytjensii. ${ }^{7-11}$ The structure of the O-PS in the remaining 7 species has not been determined.

Cronobacter is a newly emergent Gram-negative bacterial pathogen associated with severe neonatal infections through the ingestion of contaminated reconstituted infant formula. Despite the need for improved detection and profiling technologies for the detection and control of the bacterium in powdered infant formula to date the OPS of only a few Cronobacter strains has been determined from the ten recognised species. Lipopolysaccharide (LPS) isolated from Cronobacter universalis type strain NCTC $9529^{\mathrm{T}}$ was subjected to mild hydrolysis to remove the lipid A portion. The mixture of oligosaccharides and polysaccharides obtained after centrifugation was separated using size exclusion 
chromatography (SEC) on a polyacrylamide gel (Bio-Gel P-100). All collected fractions were monitored by ${ }^{1} \mathrm{H}$ NMR. For O-polysaccharide (high molecular weight fraction) analysis spectroscopic (NMR) and chemical analyses were then performed. The sugar analysis of Oantigen determined the presence of three monosaccharides: FucNAc, Man, GlcNAc in a molar ratio $\sim 2: 1: 1$. The positions of substitution of monosaccharides were determined by methylation analysis. The O-polysaccharide was hydrolysed, methylated, reduced and finally acetylated. The GC-MS analysis of the obtained partially methylated alditol acetates showed the presence of three major derivatives included in the OPS: 1,3,5-tri-O-acetyl-2,6-dideoxy-4$O$-methyl-2- $N$-methylacetamido-hexitol, 1,4,5-tri- $O$-acetyl-2,3,6-tri- $O$-methyl-hexitol, 1,3,5tri- $O$-acetyl-4,6-di- $O$-methyl-2- $N$-methylacetamido-hexitol. This indicated that the OPS chain was composed of $\rightarrow 3$-FucNAc, $\rightarrow 3$-Man, $\rightarrow 3$-GlcNAc. The absolute configurations of sugar constituents were established by GLC of $(S, R)$ - and $(S)$-but-2-yl glycosides. It was found that mannose and glucosamine possessed D configuration. L configuration of $\rightarrow 3$-FucNAc was based on analysis of glycosylation effect on ${ }^{13} \mathrm{C}$ chemical shifts, using the published rules and NMR data. ${ }^{12}$

The ${ }^{1} \mathrm{H}$ NMR spectrum (Fig. 1) showed four signals of anomeric protons at $\delta: 5.42$ (A), 5.08 (B), 4.98 (C), and 4.57 (D). There were also characteristic signals of methyl groups of 6deoxy sugars at $\delta 1.15$ and 1.18 , signals characteristic for $N$-acetyl groups in the region of $\delta$ 2.0-2.2, and remaining ring protons in the region of $\delta 3.5-4.4$. Homonuclear TOCSY and COSY spectra allowed assignment of proton signals in the monosaccharide units. These results were supplemented by interpretation of the heteronuclear HSQC and HSQC-TOCSY spectra to obtain ${ }^{13} \mathrm{C}$ chemical shifts of carbon atoms. All ${ }^{1} \mathrm{H}$ and ${ }^{13} \mathrm{C}$ chemical shifts of the OPS are shown in Table. 1. The anomeric configurations of sugar residues were assigned using ${ }^{1} J_{\mathrm{C}-1, \mathrm{H}-1}$ coupling constants obtained from the HSQC experiments recorded without decoupling. The values of $180 \mathrm{~Hz}$ for residue $\mathbf{A}, 179 \mathrm{~Hz}$ for residue $\mathbf{B}$, and $181 \mathrm{~Hz}$ for residue 
$\mathbf{C}$ revealed their $\alpha$ anomeric configuration. The value of $165 \mathrm{~Hz}$ for residue $\mathbf{D}$ identified its $\beta$ anomeric configuration. The positions of glycosylation of the monosaccharides were determined by low-field shifted signals of carbon atoms: C-3 for residue $\mathbf{A}(\delta 76.50)$, C-3 for residues $\mathbf{C}(\delta 76.67), \mathbf{C}-3$ for residue $\mathbf{D}(\delta 79.60)$, and $\mathbf{C}-4$ for residue $\mathbf{B}(\delta 76.02)$. The sequence of the sugar residues in the repeating unit of OPS was based on the interpretation of the ROESY (Fig. 2). ${ }^{13}$ On the ROESY spectrum inter-residual NOE protons contacts were observed between: A1/B4, B1/C3, C1/D3, D1/A3.

The NMR spectroscopy experiments and chemical analysis of O-polysaccharide enabled to establish a structure of the OPS of C. universalis $\mathrm{NCTC} 9529^{\mathrm{T}}$ as:

$\rightarrow 3)$ - $\alpha$-L-Fuc $p$ NAc- $(1 \rightarrow 4)-\alpha-D-M a n p-(1 \rightarrow 3)-\alpha-L-F u c p N A c-(1 \rightarrow 3)-\beta$-D-Glc $p N A c-(1 \rightarrow$
A
B
C
D

In this paper we structurally characterized the OPS isolated from $C$. universalis for the first time. Thus, there was no possibility to compare obtained results with previously published structures. However OPS of C. sakazakii G2592 possesses the same fragment in the main chain as described here O-polysaccharide of $C$. universalis NCTC $9529^{\mathrm{T}}: \rightarrow 3$ )- $\alpha-\mathrm{L}-$ Fuc $p$ NAc- $(1 \rightarrow 3)-\beta$-D-Glc $p$ NAc- $(1 \rightarrow 3)-\alpha-$-Fuc $p$ NAc- $(1 \rightarrow$ and corresponds with similarities in the sequenced O-antigen loci. ${ }^{2,14}$

\section{Experimental}

\subsection{Cultivation of $C$. universialis NCTC $9529^{\mathrm{T}}$ and LPS preparation}

C. universalis NCTC $9529^{\mathrm{T}}$ was grown on Trypticase Soy Agar (TSA). Incubation was carried out at $37{ }^{\circ} \mathrm{C}$ for $18 \mathrm{~h}$. Classical phenol-water extraction was used for LPS isolation (437 mg) out of dried bacterial cells $(8.2 \mathrm{~g}) .{ }^{10,15}$ 


\subsection{The isolation of $O$-polysaccharide}

LPS $(380 \mathrm{mg})$ was hydrolyzed with diluted acetic acid $\left(1 \% \mathrm{CH}_{3} \mathrm{COOH}, 2 \mathrm{~h}\right.$ at $\left.100{ }^{\circ} \mathrm{C}\right)$ to cleave lipid A from the sugar portion of LPS. Then the sample was centrifuged to separate the lipid A. The supernatant was evaporated in a vacuum evaporator to remove acetic acid. Then sample was dissolved in distilled water, frozen and lyophilized. The part of lyophilizate (100 $\mathrm{mg}$ ) was dissolved in distilled water and subjected to size exclusion chromatography (SEC) using Bio-Gel P-100 (Bio-councils; USA). ${ }^{10}$ Separation was carried out against deionized water on a column $(100 \times 0.9 \mathrm{~cm})$. Collected fractions were monitored by a differential refractometer detector (RI-2031 Jasco, Japan). Finally, $3 \mathrm{mg}$ of high molecular weight polysaccharide was obtained for structural analyses.

\subsection{Chemical analysis}

Sugar analysis was performed to determine the sugar composition of O-polysaccharide. The sample was hydrolyzed with trifluoroacetic acid (4M TFA, $2 \mathrm{~h}$ at $120^{\circ} \mathrm{C}$ ), reduced with sodium borohydride, and acetylated with acetic anhydride in the presence of sodium acetate $\left(120{ }^{\circ} \mathrm{C}\right.$ for $\left.2 \mathrm{~h}\right)$. Obtained derivatives were analyzed by GLC-MS technique. ${ }^{10}$ Methylation analysis was undertaken to determinate the substitution position of the monosaccharides. It was carried out using Ciukanu and Kerek method. ${ }^{16}$ DMSO was used as a solvent in the presence of solid potassium hydroxide, and then methyl iodide was added. Methylated polysaccharide was extracted with chloroform after removing any excess methyl iodide in a nitrogen stream. ${ }^{17}$ Then the methylated O-polysaccharide was hydrolyzed, reduced and acetylated, as described previously, and finally the obtained derivative were analyzed by GCMS. The absolute configurations of individual sugar units of the O-polysaccharide were determined by reaction with $(S)-(+)$-butan-2-ol. At first the polysaccharide was hydrolyzed 
$\left(2 \mathrm{M}\right.$ TFA, $\left.120{ }^{\circ} \mathrm{C}\right)$ then re- $\mathrm{N}$-acetylated $\left(1 \% \mathrm{NaHCO}_{3}\right.$ and acetic anhydride for $1 \mathrm{~h}$, at room temperature), followed by reaction with $(S)-(+)$-butan-2-ol in the presence of TFA (6h at 105 $\left.{ }^{\circ} \mathrm{C}\right)$. The obtained derivatives of butyl glycosides were analyzed by GLC. ${ }^{10,17}$

\subsection{GLC and GC-MS techniques}

GLC analysis was performed using a gas chromatograph Carlo Erba 8000 Top equipped in Flame Ionization Detector and a capillary column DB-23 $(60 \mathrm{~m})$ in the program temperature of $120-260{ }^{\circ} \mathrm{C}, 2{ }^{\circ} \mathrm{C} \mathrm{min}-1,20 \mathrm{~min}$ isotherm at $260{ }^{\circ} \mathrm{C}$. For GC-MS analysis Shimadzu GCMS-QP2010SE system equipped with Rtx-5 (30 m) capillary column was used. The same chromatographic working conditions as for GLC analysis were applied. Mass spectrometer operating conditions were as follows: EI ionization $(70 \mathrm{eV})$, the ion source temperature: 220 ${ }^{\circ} \mathrm{C}$, recorded mass range: $43-550 \mathrm{~m} / \mathrm{z}$.

\subsection{NMR spectroscopy}

NMR spectra were recorded at $308 \mathrm{~K}$ using Bruker Avance III $700 \mathrm{MHz}$ spectrometer. $2 \mathrm{mg}$ of polysaccharide was dissolved in $1 \mathrm{~mL}$ of $99 \% \mathrm{D}_{2} \mathrm{O}$ and freeze-dried to replace all exchangeable protons. The process was repeated twice, and the final sample was dissolved in $0.75 \mathrm{~mL}$ of $99.9 \% \mathrm{D} 2 \mathrm{O}$. Chemical shifts were referenced to acetone $\left(\delta_{\mathrm{H}} 2.225, \delta_{\mathrm{C}} 31.45\right)$. All 1D NMR spectra $\left({ }^{1} \mathrm{H}\right.$ and $\left.{ }^{13} \mathrm{C}\right)$ and $2 \mathrm{D}$ (COSY, TOCSY, ROESY, HSQC, and HSQC-TOCSY were registered using standard Bruker pulse programs.

\section{Acknowledgements}

This work was supported by the University of Gdansk under Grant No. 538-8220B332-14 for Ph.D. Students and Young Scientist of the Faculty of Chemistry. 


\section{References}

1. Holy, O.; Forsythe, S.J. J. Hosp. Infect. 2014, 86, 169-177.

2. Joseph, S.; Desai, P.; Li, Y.; Cummings, C. A.; Shih, R.; Degoricija, L.; Rico, A.; Brzoska, P.; Hamby, S. E.; Masood, N.; Hariri, S.; Sonbol, H.; Chuzhanova, N.; McClelland, M.; Furtado, M. R.; Forsythe S. J. PLoS ONE 2012, 7, e49455.

3. Kucerova, E.; Clifton, S. W.; Xia, X-Q.; Long, F.; Porwollik, S.; Fulton, L.; Fronick, C.; Minx, P.; Kyung, K.; Warren, W.; Fulton, R.; Feng, D.; Wollam, A.; Shah, N.; Bhonagiri, V.; Nash, W. E.; Hallsworth-Pepin, K.; Wilson, R. K.; McClelland, M.; Forsythe, S. J. PLoS ONE 2010, 5, e9556.

4. Mullane, N.; O'Gaora, P.; Nally, J. E.; Iversen, C.; Whyte, P.; Wall, P. G.; Fanning, S. Appl. Environ. Microbiol. 2008, 74, 3783-3794.

5. Jarvis, K.G.; Grim, C.J.; Franco, A.A.; Gopinath, G.; Sathyamoorthy, V.; Hu, L.; Sadowski, J.A.; Lee, C.S.; Tall, B.D. Appl. Environ. Microbiol. 2011, 77, 4017-26.

6. Sun, Y.; Wang, M.; Liu, H.; Wang, J.; He, X.; Zeng, J.; Guo, X.; Li, K.; Cao, B.; Wang, L. Appl. Environ. Microbiol. 2011, 77, 2209-14.

7. MacLean, L.L.; Pagotto, F.; Farber, J. M.; Perry, M.B. Biochem. Cell Biol. 2009, 87, 459465.

8. MacLean, L. L.; Vinogradov, E.; Pagotto, F.; Farber, J. M.; Perry, M. B. Biochem. Cell Biol. 2009, 87, 927-932.

9. MacLean, L. L.; Pagotto, F.; Farber, J. M.; Perry, M. B. Carbohydr. Res. 2009, 344, 667671.

10. Czerwicka, M.; Forsythe, S. J.; Bychowska, A.; Dziadziuszko, H.; Kunikowska, D.;

Stepnowski, P.; Kaczyński, Z. Carbohydr. Res. 2010, 345, 908-913. 
11. Czerwicka, M.; Marszewska, K.; Forsythe, S.J.; Bychowska, A.; Mazgajczyk, A.;

Dziadziuszko, H.; Ossowska, K.; Stepnowski, P., Kaczyński, Z. Carbohydr. Res. 2013, 373, 89-92.

12. Lipkind, G. M.; Shashkov, A. S.; Knirel, Y. A.; Vinogradov, E. V.; Kochetkov, N. K. Carbohydr. Res. 1988, 175, 59-75.

13. Duus, J. Ø.; Gotfredsen, C. H.; Bock K. Chem. Rev. 2000, 100, 4589-4614.

14. Arbatsky, N. P.; Wang M.; Daeva E. D.; Shashkov A. S.; Feng L.; Knirel Y. A.; Wang L. Carbohydr. Res. 2011, 346, 1169-1172.

15. Westphal, O., Jann, K. Methods Carbohydr. 1965, 5, 83-91.

16. Ciucanu, I.; Kerek, F. Carbohydr. Res. 1984, 131, 209-217.

17. Hellerqvist C. G.; Sweetman B. J. Methods of Biochemical Analysis, 1990, 34, 91-141. 


\section{Table 1}

${ }^{1} \mathrm{H}$ and ${ }^{13} \mathrm{C}$ NMR data of the O-polysaccharide isolated from C. universalis NCTC $9529^{\mathrm{T}}$.

Underlined values indicate position of substitution.

\begin{tabular}{|c|c|c|c|c|c|c|}
\hline \multirow[b]{2}{*}{ Residue } & \multicolumn{6}{|c|}{ Chemical shifts (ppm) ${ }^{1} \mathrm{H}$ and ${ }^{13} \mathrm{C}$} \\
\hline & $\mathrm{H} 1$ & $\mathrm{H} 2$ & $\mathrm{H} 3$ & $\mathrm{H} 4$ & H5 & H6 \\
\hline${ }^{1} J_{\mathrm{C}-1, \mathrm{H}-1}(\mathrm{~Hz})$ & $\mathrm{C} 1$ & $\mathrm{C} 2$ & $\mathrm{C} 3$ & $\mathrm{C} 4$ & $\mathrm{C} 5$ & C6 \\
\hline$\rightarrow 3$ )- $\alpha$-L-Fuc $p$ NAc (A) & 5.42 & 4.08 & 4.07 & 3.80 & 4.01 & 1.18 \\
\hline 180 & 97.91 & 49.27 & $\underline{76.50}$ & 70.03 & 67.60 & 16.55 \\
\hline \multirow[t]{2}{*}{ NAc } & - & 2.04 & & & & \\
\hline & 175.23 & 23.18 & & & & \\
\hline$\rightarrow 4)$ - $\alpha$-D-Manp (B) & 5.08 & 3.86 & 4.07 & 4.38 & 4.3 & $3.65 / 3.56$ \\
\hline 179 & 101.96 & 69.54 & 71.48 & $\underline{76.02}$ & 72.61 & 63.53 \\
\hline$\rightarrow 3$ )- $\alpha$-L-Fuc $p$ NAc (C) & 4.98 & 4.28 & 3.98 & 3.81 & 4.41 & 1.15 \\
\hline 181 & 98.94 & 49.27 & $\underline{76.67}$ & 72.3 & 67.92 & 16.22 \\
\hline \multirow[t]{2}{*}{ NAc } & - & $2 ., 02$ & & & & \\
\hline & 175.45 & 23.45 & & & & \\
\hline$\rightarrow 3$ )- $\beta$-D-Glc $p$ NAc (D) & 4.57 & 3.83 & 3.69 & 3.51 & 3.48 & $3.77 / 3.96$ \\
\hline 165 & 100.73 & 56.74 & $\underline{79.60}$ & 69.54 & 76.83 & 61.92 \\
\hline \multirow[t]{2}{*}{ NAc } & - & 1.96 & & & & \\
\hline & 175.1 & 23.18 & & & & \\
\hline
\end{tabular}




\section{Figure legends}

Fig. 1. ${ }^{1} \mathrm{H}$ NMR spectrum of the O-polysaccharide isolated from C. universalis NCTC $9529^{\mathrm{T}}$. The letters refer to the monosaccharide residues as defined in Table 1.

Figure 2. The section of ROSY spectrum of the O-polysaccharide from C. universalis NCTC $9529^{\mathrm{T}}$. The letters refer to the monosaccharide residues as defined in Table 1. Numbers refer to the protons in monosaccharide. Inter- residual NOE contacts are underlined. 
Fig. 1.

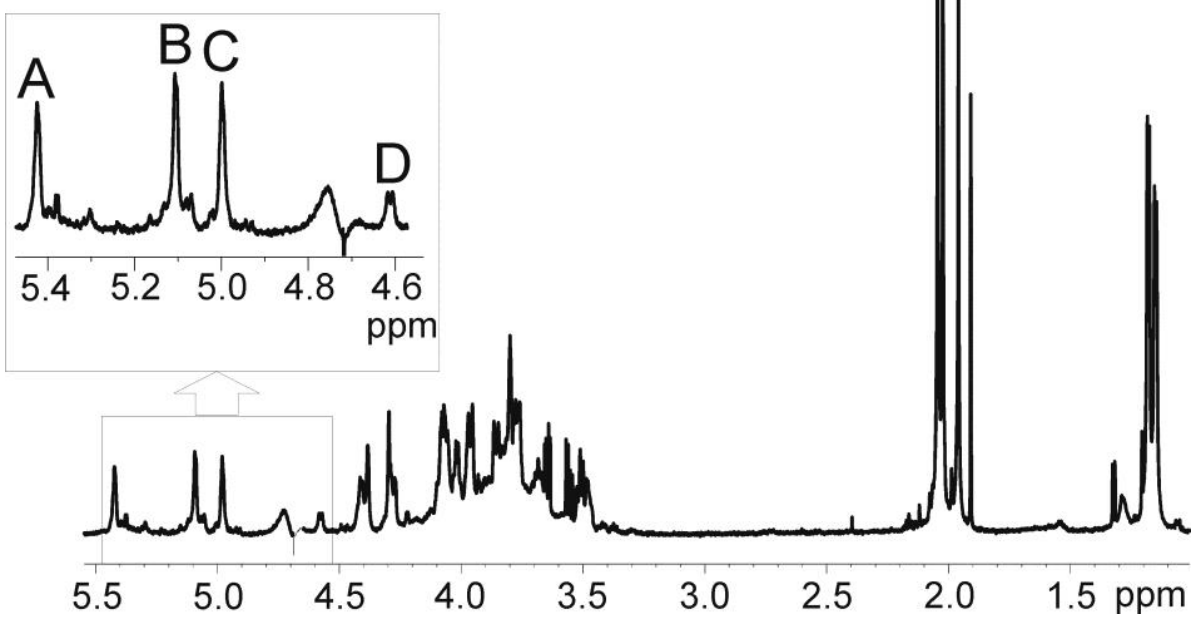


Fig. 2.

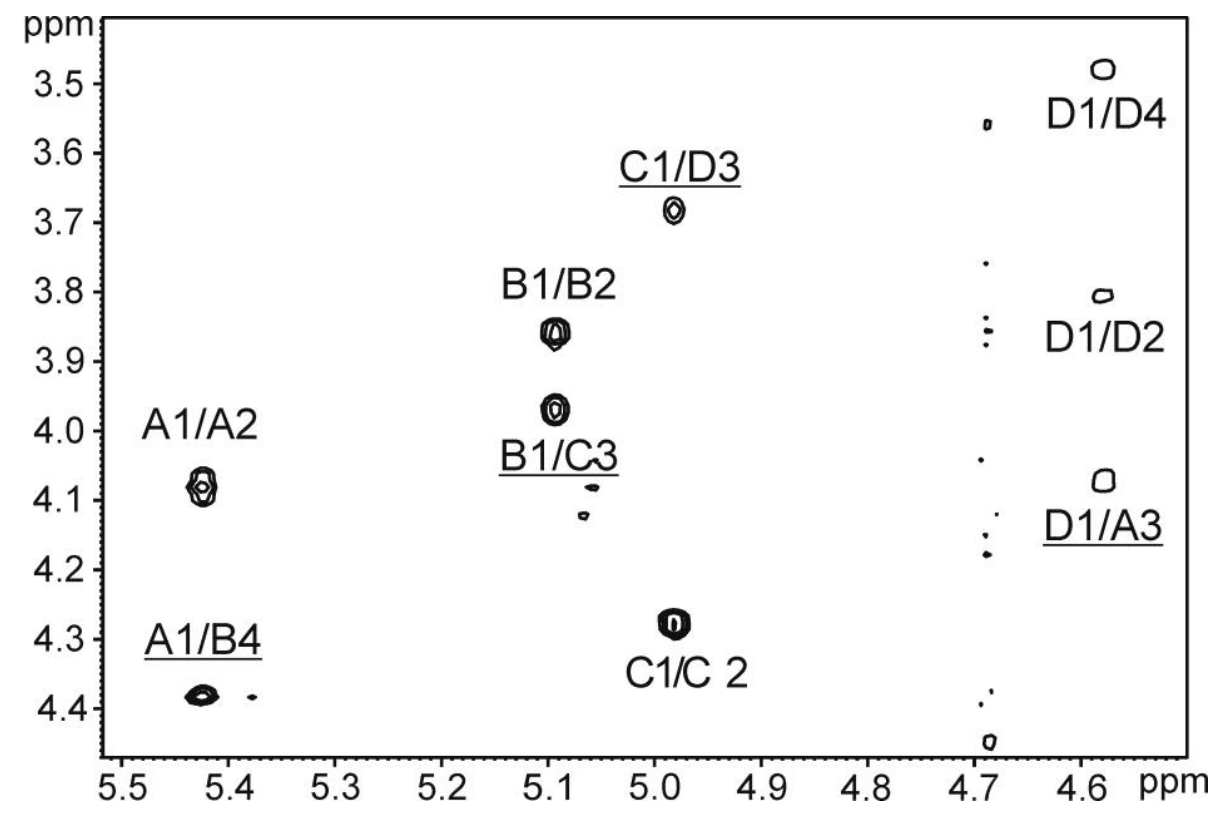

